\title{
An Abscess Developing in an Old Subcutaneous Tunnel after Catheter Diversion
}

\author{
Chiaki Kimura ${ }^{1}$, Rikako $\mathrm{Oki}^{2}$, Yoshifumi Hamasaki ${ }^{2}$ and Masaomi Nangaku ${ }^{2}$
}

Key words: peritoneal dialysis, exit site infection, tunnel infection, catheter diversion procedure, abscess

(Intern Med 60: 813-814, 2021)

(DOI: 10.2169/internalmedicine.5839-20)
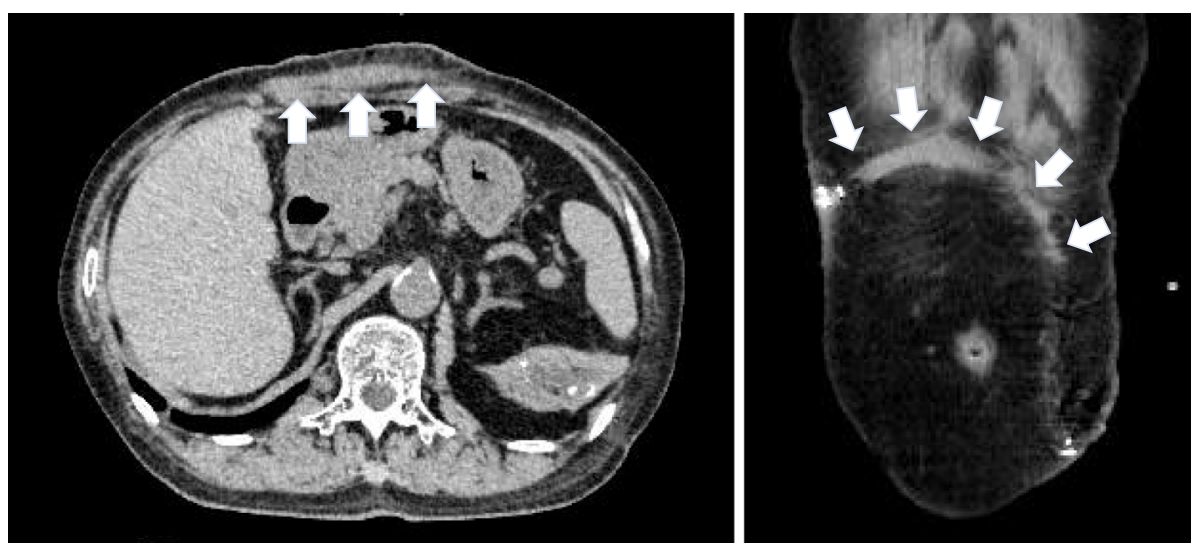

Picture 1.

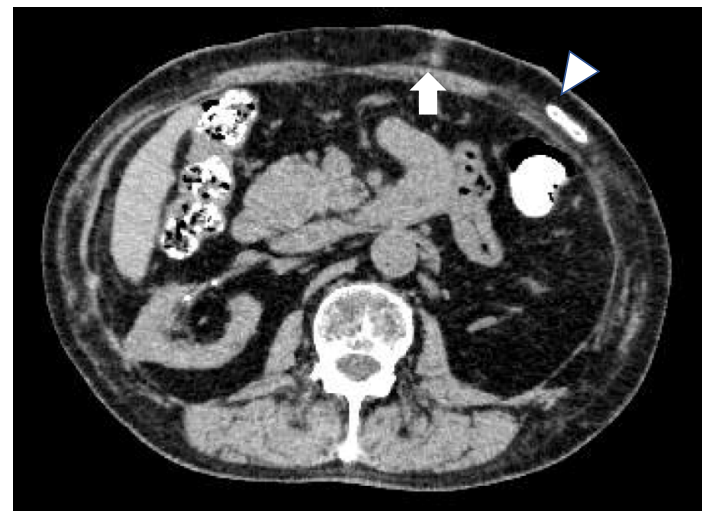

Picture 2.

A 72-year-old man with end-stage renal disease due to cystinuria had been receiving peritoneal dialysis (PD) for over five years. Because the exit site and tunnel infection caused by coagulase negative staphylococci worsened, catheter diversion procedure was performed. The extraperito- neal part of the PD catheter was surgically replaced without involving the peritoneum (1). No bacteria were detected by a culture of the old cuff. Eight days later, despite of continuing the administration of vancomycin, redness and induration along the old subcutaneous tunnel was found by physical examination. Purulent fluid was drained by an ultrasonographic-guided diagnostic puncture. Corynebacterium amycolatum and Prevotella melaninogenica, uncommon causative organisms of PD catheter-related infection, were detected in the purulent fluid (2). Computed tomography revealed the presence of an abscess throughout the old subcutaneous tunnel (arrows, Picture 1,2) but there was no spread to the new one (arrowhead, Picture 2). Urgent open drainage of the old subcutaneous tunnel was conducted. The abscess was thus successfully treated. The prompt, proper diagnosis and management of a PD catheter-related infection enabled the patient to continue PD without catheter removal (2).

The authors state that they have no Conflict of Interest (COI).

${ }^{1}$ Division of Nephrology and Endocrinology, The University of Tokyo Hospital, Japan and ${ }^{2}$ Department of Hemodialysis and Apheresis, The University of Tokyo Hospital, Japan

Received: July 12, 2020; Accepted: August 5, 2020; Advance Publication by J-STAGE: September 30, 2020

Correspondence to Dr. Yoshifumi Hamasaki, yhamasaki-tky@umin.ac.jp 


\section{References}

1. Clouâtre Y, Cartier P, Charbonneau R, Déziel C, Allard M, Madore F. Outpatient CAPD catheter salvage for persistent exitsite/tunnel infection. Nephrol Dial Transplant 15: 231-234, 2000.

2. Szeto CC, Li PK, Johnson DW, et al. ISPD catheter-related infec- tion recommendations: 2017 update. Perit Dial Int 37: 141-154, 2017.

The Internal Medicine is an Open Access journal distributed under the Creative Commons Attribution-NonCommercial-NoDerivatives 4.0 International License. To view the details of this license, please visit (https://creativecommons.org/licenses/ by-nc-nd/4.0/).

(C) 2021 The Japanese Society of Internal Medicine Intern Med 60: 813-814, 2021 